\title{
Coping Strategies among Farmers and Herders during Post Conflict Situation in the Kainji Dam Area of Yauri Emirate, Kebbi State Nigeria
}

\author{
Umar, S
}

\author{
Department of Agricultural Economics and Extension \\ Kebbi State University of Science and Technology, Aliero-Nigeria \\ B.F. Umar
Department of Agricultural Extension
Usmanu Danfodiyo University, Sokoto-Nigeria
}

A.I. Illo

Department of Agricultural Economics and Extension Kebbi State University of Science and Technology, Aliero-Nigeria

\section{Doi:10.5901/jesr.2013.v3n9p59}

\section{Abstract}

This study examines the coping strategies among farmers and herders during post-conflict situation in Kainji dam area of Yauri Emirate, Kebbi State Nigeria. The study was conducted in the 3 Local Government Areas of the Emirate. Purposive sampling was used to select twelve villages in the LGAs (4 villages/ LGA). 16 respondents were randomly selected for data collection, to obtain a total of 192 respondents. The result of the study reveals that the average uses of problemoriented coping strategies score among farmers were $51.8 \%$, Herders $50.5 \%$. The use of emotionoriented coping strategies score among farmers and herders were $38.4 \%, 59.7 \%$, respectively and the average use of social support coping strategies among farmers and herders were $30.0 \%$, $28.5 \%$ respectively. The study recommends that Government and other donor organizations should assist the conflict actors with relief materials during conflict situation, so that they can cope with the stress and resume normal production activity.

\section{Introduction}

The field of stress and coping emerged more than three decades ago from the recognition of the dynamic interaction between person and environment (Lazarus and Folkman, 1984). In recent years, the field has been trying to introduce more realism to stress and coping research, as the contextual research of the last two decades yielded few solid findings that made a difference in people's lives (Somerfield and McCrae, 2000). One of the most important neglected contexts is culture. We believe that culture is a fundamental context that helps to shape both the individual and the environment.

Scholarly definitions of stress highlight that it is a combination of psychological and physical reactions to events that evoke individual responses (Franken 1994). Research on stress has focused on the physiological expression of stress and its impact on the individual as well as on models of interaction between the environment and the individual coping and resilience (Franken 1994; Somerfield and McCrae 2000). Immediate physiological responses to stress involve reactions from the autonomic nervous system, which is believed to allow a person a chance to react quickly to perceived danger (Mitchell and Everly 1996).

Conflict actors employ coping strategies in order to protect their psychological intactness. 
Effective strategies should enhance their psychological adaptation despite the traumatic stress. Research has not, however, provided a generally valid differentiation between effective and ineffective coping strategies. Some evidence shows that problem-focused and active coping correlates negatively, and emotion-focused coping correlates positively, emotional and behavioral problems (Compas, Worsham, Ey and Howell, 1996). Yet others have not found beneficial effects of problem-focused and active coping in predicting psychological adjustment (Rogers and Holmbeck, 1997). Similarly, the findings on the role of avoidance versus approach coping in enhancing psychological adjustment are somewhat mixed. Some researchers obtained evidence that avoidance coping strategies, especially denial and distraction, are associated with poor psychological and social adjustment (Kliewer et al., 1998), while others maintain that coping effectiveness depends on the nature of stress (Band and Weiss, 1988).

Lazarus and Folkman (1984) conceptualized two broad response dimensions among people facing stress: emotion focused coping involves modifying one's own feelings and controlling distress, and problem-focused coping activities are aimed at changing the stressful situation. Critics have noted that emotion- and problem-focused distinction between coping strategies may be simplistic (Lazarus, 2000). Multidimensional theory, involving the orientation and modality of coping, can correspond more accurately to resource use conflict actors' various efforts to deal with adversities and demands in their lives. Active coping involves direct problem solving, cognitive decision making, and restructuring. Distraction refers to replaced action and physical release of emotions. Avoidance involves behavioral (withdrawal) and cognitive (denial and refusing to think about the trauma) strategies. Support-seeking consists of emotional sharing and solving the problem with the help of others.

\section{Methodology}

The Kainji hydroelectric dam project was Nigeria's largest project in the 1962-68 National Development Plans, which was completed in 1968. Kainji dam is 136 kilometers long and 24 kilometers at the widest section with a surface area of 1.25 million square meters and a storage capacity of 15 billion cubic meters, of which the useable storage is 11.5 billion cubic meters of water (Hybrid Design Associates Environmental Consultants, 2002).

Yauri Emirate comprises of three Local Government Areas, namely Yauri with headquarters at Yelwa, Ngaski with headquarters at Wara and Shanga with headquarters at Shanga. The area falls within about $80 \%$ of the total area of the Kainji Lake. It is located on latitude $11^{0} 15^{1}-12^{0} 30^{1} \mathrm{~N}$ and longitude $5^{0} 18^{1}-11^{0} 20^{1} \mathrm{E}$. The area is situated in the Guinea Savanna vegetation zone of Nigeria where the average annual rainfall is about $1000 \mathrm{~mm}$. It has a minimum temperature of $32^{\circ} \mathrm{C}$ (Yauri Meteorological Station, 2012). The Emirate has a population of The Emirate has a population of 353,808 people. Out of this figure 100,564 reside within Yauri local Government LGA, while 127,142 and 126,102 were found in Shanga and Ngaski LGA respectively (National Population Commission, 2012. Farming is the major occupation of the inhabitants of the Kainji lake area, although they also engage in herding, fishing, trading and other informal sector activities.

\subsection{Sampling Technique and Data Analysis}

The study was conducted in the three Local Government Areas of Yauri Emirate. Purposive sampling was used to select twelve villages in the LGAs (4 villages/ LGA). Sixteen respondents (10 farmers, 6 herders) were randomly selected from each village to obtain a total of 192 respondents. The data collected for the study was analyzed using descriptive statistics. 


\section{Results and Discussion}

\subsection{Coping Strategies among Farmers Involved in Conflicts}

Coping strategies of resource users were classified into three namely: problem-oriented coping strategies (POCS), emotion-oriented coping strategies (EOCS) and social-support coping strategies (SSCS). The use of each strategy among farmers, herders and fishermen were investigated. Table 1 shows the descriptive statistics of the use of problem-oriented strategies among the farmers. Farmers generally used a combination of strategies, as no single strategy is enough to bring the needed succor to the harm caused by conflict. Ten strategies were identified, out of which "buying foodstuff for the family' was found to be the most often used coping strategy by the farmers $(79.2 \%)$, while herders most often used working harder $(83.4 \%)$ and fishermen most often used abandoning fishing for other jobs $(75.0 \%)$. The herders generally used less of problem-oriented coping strategies than the farmers and fishermen. This perhaps is an indication that farmers and fishermen considered the conflict situation from the 'problem' perspective more than the herders. The herders probably faced less problems or direct consequences of the conflict than the farmers and fishermen.

Other most often used POCS by the farmers are: use of previous farming experience $(73.3 \%)$, abandoning farming and taking up alternative occupation $(70.8 \%)$, working harder $(69.2 \%)$, and taking loans from friends and families $(58.3 \%)$. The fact that majority of the farmers claimed to buy foodstuff for home consumption may indicate the severity of the effect of destruction of their crops. The importance of job experience came to the fore, as respondents claimed to rely on their previous experiences to cope with the conflict situation. It could imply that respondents with long experience may be able to cope better than those that possessed lesser experience. Abandoning farming to take other jobs was also found to be the next adopting strategy by farmers. The outcome of focus group discussion with farmers revealed that this strategy, coupled with other problem-coping strategies as indicted in Table 4.23 'sowed less $(40.8 \% \%$ and sold farm $(36.7 \%)$ was found to cause declining crop production in the area, which might be an indication of food insecurity in the communities. Other farmers (35.8\%) prepared for worst, to attack herders whenever their crops were subsequently destroyed, and $29.2 \%$ used charms. The least used POCS was tightened of farm security $(24.2 \%)$.

The result of focus group discussion further revealed that abandoning farming and herding for illegal gold mining was found to be a common practice among some people in Yauri Emirate, particularly the youth. This people troop in hundreds at Laka, Tungar Bature, Mararraban-Yauri, Kambu and Kimo villages during the rainy and dry seasons and engaged in illegal gold mining.

Farmers most often used prayer for peace $(79.2 \%)$ as the first EOCS during the aftermath of conflicts, indicating their level of religious attachment in the study area. Accepting the conflict situation/consequences as an act of fate $(77.5 \%)$ was found to be the second most commonly used emotion-oriented coping strategy among farmers. The ability of the farmers to accept the situation with equanimity is not only a psychological coping strategy, but is also capable of reducing the escalation of violent conflict between the aggrieved groups.

Pretending that the conflicts was not bad $(25.0 \%)$, appease of the other party $(25.0 \%)$, Transfer of aggression (14.2\%) and use of drugs/alcohol $(9.2 \%)$ are found to be the least EOCS adopted by the farmers in the study area. Some farmers that indicated that the conflicts were not bad attributed their reasons to the exploitative nature of the monetary compensation they receive from the herders that destroyed their crops. It is instructive to observe that most of the farmers do not use drug/alcohol as a coping strategy because they became aware that they portend undesirable health consequences and worsen the conflict situation by affecting the behavioral orientations of persons concerned. 
Table 1: Distribution of the Farmers According to Coping Strategies $(n=120)$

\begin{tabular}{lccc}
\hline \multicolumn{1}{c}{ Coping strategy } & Used & Uncertain & Not used \\
\hline Problem oriented & & & \\
Working harder & $83(69.2)^{*}$ & $12(10.0)$ & $25(20.8)$ \\
Using experience & $88(73.3)$ & $23(19.2)$ & $9(7.5)$ \\
Borrowing money & $70(58.3)$ & $18(15.0)$ & $32(26.7)$ \\
Preparing for the worst & $43(35.8)$ & $11(9.2)$ & $66(55.0)$ \\
Selling farm & $44(36.7)$ & $13(10.8)$ & $63(52.5)$ \\
Buying food stuff & $95(79.2)$ & $6(5.0)$ & $19(15.8)$ \\
Sowing less & $49(40.8)$ & $7(5.8)$ & $64(53.3)$ \\
Shifting to another job & $85(70.8)$ & $6(5.0)$ & $29(24.2)$ \\
Tightening farm security & $29(24.2)$ & $46(38.3)$ & $45(37.5)$ \\
Using charms & $35(29.2)$ & $29(24.2)$ & $56(46.7)$ \\
Average \% & $\mathbf{( 5 1 . 8 )}$ & $\mathbf{( 1 4 . 2 )}$ & $\mathbf{( 3 4 . 0 )}$ \\
Emotion-oriented & & & \\
Accepting conflict as fate & $93(77.5)$ & $6(5.0)$ & $21(17.5)$ \\
Praying for peace & $95(79.2)$ & $6(5.0)$ & $19(15.8)$ \\
Pretending the conflict wasn't bad & $30(25.0)$ & $18(15.0)$ & $72(60.0)$ \\
Transferring of aggression & $17(14.2)$ & $16(13.3)$ & $87(72.5)$ \\
Using drugs alcohol & $11(9.2)$ & $24(20.0)$ & $85(70.8)$ \\
Appeasing other party & $30(25.0)$ & $16(13.3)$ & $74(61.7)$ \\
Average \% & $\mathbf{( 3 8 . 4 )}$ & $\mathbf{( 1 1 . 9 )}$ & $\mathbf{( 4 9 . 7 )}$ \\
Support seeking & & & \\
Help from relations & $86(71.7)$ & $0(0)$ & $34(28.3)$ \\
Help from local leaders & $27(22.5)$ & $8(6.7)$ & $85(70.8)$ \\
Help from local government & $20(16.7)$ & $6(5.0)$ & $94(78.3)$ \\
Sought litigation & $11(9.2)$ & $5(4.2)$ & $104(86.7)$ \\
Average \% & $\mathbf{( 3 0 . 0 )}$ & $\mathbf{( 3 . 9 )}$ & $\mathbf{( 6 6 . 1 )}$ \\
\hline
\end{tabular}

* Figures in brackets are percentages of the coping strategies

Source: Field survey 2011

Table 1 also illustrates that seeking assistance from friends and relatives was found to be the most commonly used SSCS among the farmers $(71.7 \%)$ to ameliorate the effects of conflict. It was followed by seeking help from traditional institutions $(22.5 \%)$ and local government $(16.7 \%)$. Discussions with the farmers revealed that referring to traditional leaders and the local government for assistance to cope with the conflicts is usually regarded as a last resort, because they do not offer such assistance. A small proportion of the farmers (9.2\%) used litigation as a coping strategy, despite the fact that there are regulations regarding the use of agricultural land in the study area. This might be attributed to the findings of UNIFCPA, (2010) who reported that in conflict-affected areas, resource use managing institutions have often been weakened, politicized, and delegitimized, and may not play a constructive role in the resolution of disputes.

\subsection{Coping Strategies among Herders Involved in Conflicts}

The results from table 2 shows that majority of the respondents (83.4\%) employ working harder as a coping strategy among herders, might indicate the comparative resilience of the respondents in the face of unfavorable situations. It is worrisome, however, that as much as $79.2 \%$ of the herders adopted 'reduced size of herds' as coping strategy. Outcome of the focus group discussion with herders revealed that herders sold certain part of their herds to either pay compensation to the farmers for the crops destroyed, used the money to bribe conflicts management institutions or to engage in litigation. The herders attributed the continuous declining size of their herds to conflicts. They added that some herders' size declined while that of other herders were completely lost, thus 
they resorted to engage in herding contract as laborers (biro) i.e. herding for other herders/cattle owners. The herders therefore concluded that in recent days, some of the Fulani (most especially youths) engaged in robbery as a result of loss of means of their livelihood. As a result of the alleged criminal records of the herders' youths, Migrant herders are mostly denied access to settle in the study area until a confirmation was received from the community leader of the previous location of the herders exonerating them from any criminal activity.

The results further show that the herders were perhaps more security conscious $(73.6 \%)$ than the farmers. Herders tighten the security of their herds in anticipation of reprisals from the farmers for destruction of their crops, thus the herders used charms $(63.9 \%)$ and prepare for the worst $(66.7 \%)$ to attack the farmers. This scenario tends to indicate that herders were probably more bellicose or inclined to fight than the farmers. The herders most commonly perceived that the conflict was not bad $(75.0 \%)$ as EOCS during the aftermath of conflicts. The farmers attributed this position of the herders to the superstitious belief that if the herders' flocks feed on the farmers' crops, the productivity of the herders' animal would increase. Regarding the conflict situation/consequences as an act of fate $(65.3 \%)$ was found to be the second most commonly used emotion-oriented coping strategy among the herders.

Table 2: Distribution of the Herders according to coping strategies $(n=72)$

\begin{tabular}{lccc}
\hline \multicolumn{1}{c}{ Coping strategy } & Used & Uncertain & Not used \\
\cline { 2 - 2 } & Problem oriented & & \\
Working harder & $60(83.4)^{*}$ & $6(8.3)$ & $6(8.3)$ \\
Using experience & $45(62.5)$ & $7(9.7)$ & $20(27.8)$ \\
Borrowing money & $16(22.2)$ & $9(12.5)$ & $47(65.3)$ \\
Preparing for the worst & $48(66.7)$ & $7(9.7)$ & $17(23.6)$ \\
Selling herds & $14(19.4)$ & $4(5.6)$ & $54(75.0)$ \\
Buying food stuff & $18(25.0)$ & $4(5.6)$ & $50(69.4)$ \\
Reducing stock & $57(79.2)$ & $4(5.5)$ & $11(15.3)$ \\
Shifting to another job & $6(8.3)$ & $5(6.9)$ & $61(84.8)$ \\
Tightening herd security & $53(73.6)$ & $4(5.6)$ & $15(20.8)$ \\
Using charms & $46(63.9)$ & $6(8.3)$ & $20(27.8)$ \\
Average \%o & $\mathbf{( 5 0 . 5 )}$ & $\mathbf{( 7 . 7 )}$ & $\mathbf{( 4 1 . 8 )}$ \\
Emotion-oriented & & & \\
Accepting conflict as fate & $47(65.3)$ & $3(4.2)$ & $22(30.6)$ \\
Praying for peace & $43(59.7)$ & $3(4.2)$ & $25(34.7)$ \\
Pretending conflict wasn't bad & $54(75.0)$ & $3(4.2)$ & $15(20.8)$ \\
Transferring of aggression & $28(38.9)$ & $3(4.2)$ & $41(57.0)$ \\
Using drugslalcohol & $40(55.6)$ & $5(6.9)$ & $27(37.5)$ \\
Appeasing other party & $46(63.9)$ & $5(6.9)$ & $21(29.1)$ \\
Average \% & $\mathbf{( 5 9 . 7 )}$ & $\mathbf{( 5 . 3 )}$ & $\mathbf{( 3 5 )}$ \\
Support seeking & & & \\
Help from relations & $46(63.9)$ & $3(4.2)$ & $23(32.0)$ \\
Help from local leaders & $\mathbf{1 4}(19.5)$ & $5(6.9)$ & $53(73.6)$ \\
Help from local government & $11(15.3)$ & $4(5.6)$ & $57(79.1)$ \\
Sought litigation & $11(15.3)$ & $23(31.9)$ & $39(52.8)$ \\
Average \% & $\mathbf{( 2 8 . 5 )}$ & $\mathbf{( 1 2 . 2 )}$ & $\mathbf{( 5 9 . 4 )}$ \\
\hline
\end{tabular}

* Figures in brackets are percentages of the coping strategies

Source: Field survey 2011

Use of appease of the other party/payment of compensation for the crop destroyed to avoid litigation $(63.9 \%)$ was found to be higher among herders than farmers. This might indicate that farmers were more at the receiving end and needed to be appeased by the herders, and other conflicts actors involved. It also, perhaps, shows that the herders and other conflict actors might be 
willing to compensate the obviously aggrieved farmers. But the outcome of focus group discussion with the herders revealed that some herders are not always willing to pay compensation to the aggrieved farmers, but rather prefer giving bribe to the traditional leaders to dismiss the case or using the money to engage in litigation.

The farmers added that the herders hold the view that if the compensation was paid to the farmers, they will keep reporting subsequent destruction of their farm crops. The traditional leaders reported however, that they devised a strategy of assessing the farmers' crop damages for payment of compensation without the knowledge of the herders, and forward same amount for collection as bribe to the farmers. This arrangement clearly indicates the weakness of the traditional institutions in managing resource use conflicts. Some herders (mostly elders) prayed for peace $(59.7 \%)$ as a coping strategy. Other coping strategies that are found to be adopted by herders include use of drugs/alcohol (55.6\%) and transfer of aggression (38.9\%). Focus group discussion confirms that some herders resorted to destroy other farmers' crops as reprisal for payment of compensation.

Table 2 further illustrates that the use of seeking assistance from friends, relatives and the herders' association (Miyetti Allah Cattle Breeders Association (MACBAN) was the most often used SSCS $(63.9 \%)$ among the herders. It was followed by seeking help from traditional institutions $(19.5 \%)$. Engaging in litigation and seeking assistance from the local government were found to be the least coping strategies adopted by the herders.

\section{Conclusion and Recommendations}

The stress coping strategies employed by the resource users were classified into three namely: problem oriented (POCS), emotion oriented (EOCS) and social support seeking coping strategies (SSCS). The average uses of problem-oriented coping strategies score among farmers were found to be $51.8 \%$, Herders $50.5 \%$. While the uses of emotion-oriented coping strategies score among farmers and herders were $38.4 \%, 59.7 \%$, respectively and the average use of social support coping strategies among farmers and herders were $30.0 \%, 28.5 \%$ respectively.

The study recommends that it is imperative to mainstream the peculiarities of the conflict actors/victims' coping strategies into the management of natural resource conflicts through the following:

- Yauri Emirate should establish Co-management Committee on natural resources that would ensure that farmers, herders and fishermen adhere strictly to the laid down rules and regulation governing the use of the natural resources in the study area.

- Government and other donor organizations should assist the conflict actors with relief materials during conflict situation, so that they can cope with the stress that results from the conflict and resume normal production activity.

\section{References}

Band, E.B., and Weiss, J. R. (1988). How to feel better when it feels bad: Children's perspectives on coping with everyday stress. Developmental Psychology, 24, 247-253.

Compas, B.E., Malcarne, V.L., \& Fondacoro, K.M. (1988). Coping with stress in older children and young adolescents. J ournal of Consulting and Clinical Psychology, 56, 405-411.

Franken, R. E. (1994). Human motivation, 3rd ed. Belmont: Brooks/Cole. 21pp.

Hybrid Design Associates Environmental Consultants, (2002). Socioeconomic and environmental impact study of Kainji Hydroelectricity dam on Yauri Emirate. Unpublished report submitted to Yauri Emirate council committee on HYPPADEC, Yauri. Pp.1-45.

Kliewer, W., Lepore, S.J., Oskin, D., \& J ohnson, P.D. (1998). The role of social and cognitive processes in children's adjustment to community violence. Journal of Clinical and Consulting Psychology, 66, 199-209.

Lazarus, R. S. and S. Folkman (1984). Stress, Appraisal and Coping. New York, Springer Publishing 
Company. In Adisa, R.S. (2008). Land Use Conflict between Farmers and Herdsmen Implications for Agricultural and Rural Development in Nigeria Department of Agricultural Extension and Rural Development, University of Ilorin, Nigeria. 46-48.

Lazarus, R.S. (2000). Toward better research on stress and coping. American Psychologist, 55, 665-673.

Mitchell, J. T., and Everly, G. S. (1996). Critical incident stress debriefing: an operations manual. Ellicott City: Chevron. 31pp.

National Population Commission, (2012). Report on 2012 Population census, Kebbi State, Nigeria. 33pp. Rogers, M.J., and Holmbeck, G.N. (1997). Effects of interparental aggression on children's adjustment: The moderating role of cognitive appraisal and coping. Journal of Family Psychology, 11, 125-130.

Somerfield,M., and McCrae, R. (2000). Stress and coping research: Methodological challenges, theoretical advances, and clinical applications. American Psychologist, 55, 620-625. doi:10.1037/0003066X.55.6.620.

United Nations Interagency Framework for Coordination on Preventive Action (UNIFCPA) (2010). Capacity Development for Managing Land and Natural Resource. Guidance Notes for Practitioners, prepared by UNDP. 99-101.

Yauri Meteorological Station (2012). National Meteorological Agency, Kebbi State. 13pp. 
